\title{
Silence please!
}

\section{Jane Maeve O' Sullivan}

School of Applied Social Studies, UCC

\section{Introduction}

"Shut up and eat your dinner!" Given that I grew up in an era in which it was considered that children should be seen and not heard the preceding demands were not at all unusual and regularly demanded at our family dinner table. In the not-so-distant past children were viewed as empty vessels in need of being filled with knowledge and "manners". Their role was not to question but to accept the guidance, wisdom and discipline of knowing adults. Our view of childhood, however, has evolved. Today we recognise that children play an active role in their own lives and development. Instead of viewing children as human becomings we recognise them as human beings, as citizens, and like all citizens, children hold rights. In 1992 Ireland ratified the United Nations Convention on the Rights of the Child (CRC). Amongst other rights, this treaty affords children the right to be heard. Specifically, Article 12 of the convention states that children have the right to voice an opinion in any matter that effects them and that their opinion must be considered in any decisions concerning them, in accordance with their age and maturity. Research has found that as a society we are making progress, children's voices are increasingly being included within the community and the family context. Within the school context, however, this right is proving to be problematic. This research will explore why.

\section{Participation}

The term participation has become shorthand for the rights contained within Article 12 of the CRC, that is, children's right to be heard and to contribute to decisions affecting them. An extremely wide range of activities and projects are clustered under the umbrella of participation, from everyday decisions within daily family life to public protests that challenge adult authority. Broadly speaking participation can be divided into two categories: formal and informal. Formal participatory mechanisms include youth parliaments, school councils and children's participatory research while informal participation refers to children being heard and contributing to decisions within their everyday lives. In the last thirty years or so children's participation has received considerable academic and policy focus as the pressure mounts to recognise children as rights holders. Through formal participatory mechanisms, children as a collective are beginning to have a voice within society and within policy development, while individually children are now afforded a voice in judicial or administrative proceedings. Notwithstanding these benefits, formal 
participation has been criticized for its failure to facilitate all children's rights to be heard within their everyday lives. The numbers of children involved in formal participation is a very small percentage of the whole. Furthermore, it is often articulate middle-class children who are involved in these mechanisms which is unfortunate given that marginalized, disadvantaged or vulnerable children, i.e. the very children most in need of being heard, are the ones least likely to be involved in formal participation.

While the focus has, to date, been on the promotion of formal rather than informal participation, in recent years there has been a growing appreciation regarding the need to create meaningful participation for all children within the everyday spaces they occupy. In other words, to make sure all children can enjoy their right to be heard within their everyday lives. It has been argued that a greater emphasis should be put on creating informal participatory spaces within children's everyday lives rather than the previous emphasis on formal mechanisms/spaces such as school councils and youth parliaments and that recognition must be given to children's spontaneous participation which occurs within their everyday mundane lives and interactions. We must work to develop a culture in which we listen to all children and give genuine consideration to their perspectives. What children think and feel about any issue that impacts on them must matter. Given, therefore, that the vast majority of children spend up to half of their waking lives in school it is vital that we work to support children's informal participation within the school context.

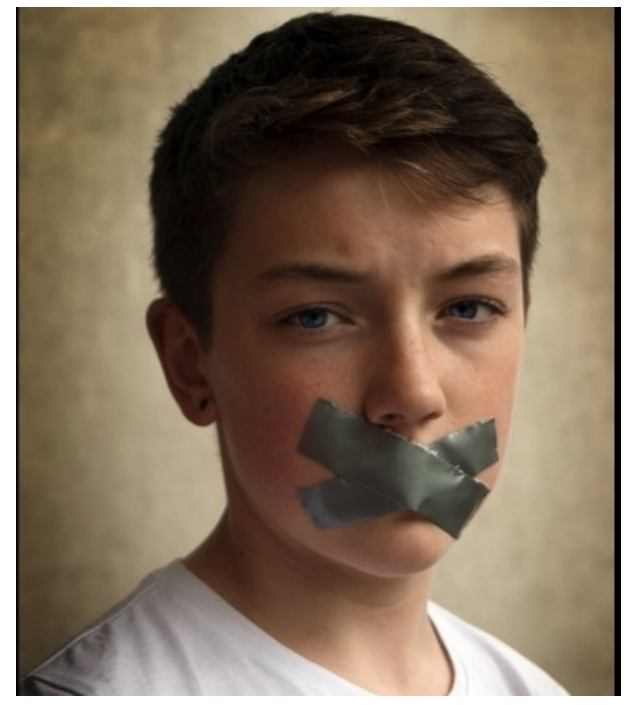

Figure 1: Image used courtesy of Wissam Abdel Samad

In order to promote and support the participation of all children within their everyday lives it has been argued that we need to re-frame research on children's participation by re-positioning adult/child relations and the spaces in which they occur as the central focus. In other words instead of focusing on the merits or success of particular participatory mechanisms and projects, as research on participation has traditionally done, we need to look to how the relationships between an adult and a child impacts on the likelihood of the child being heard, while also examining the impact of the context in which that relation- 
ship occurs on the level of participation the child is afforded. This approach is particularly appropriate for the exploration of children's right to be heard given that facilitating this right requires a negotiation between child and adult. This negotiation is influenced by the nature of the relationship between the child and the adult as well as the context in which this negotiation takes place (e.g. school, home etc.). Adults, therefore, play a vital role in supporting children to avail of their right to be heard/participate, with teachers being key to the implementation of this right within a school context. The relationship between teachers and their pupils is determined by many factors including the numerous constraints and structures (such as pupil/teacher ratios and curriculum demands) that teachers must work within, the teacher's perspective on what is appropriate for children, their own role as a teacher and the culture within the school.

\section{Research Question and Methods}

The aim of my research is to identify the factors that either support or prevent children from enjoying their right to be heard within a primary school context. To achieve this I am focusing on the relationships between teachers and pupils and the spaces in which they occur. I am in the process of visiting up to five primary schools. In each school I begin by interviewing the principal following which I spend up to a week observing in two different classrooms. I then interview the teacher from both classrooms and finally conduct two focus groups with small groups of children from both classes. This approach allows me to observe the relationship/interactions between students and teachers while also giving me the opportunity to glean both children's and adults' perspectives regarding the issue of being heard. Once all the data has been gathered it will be critically analysed manually and also using computer assisted qualitative data analysis in order to identify both the factors that serve as barriers and also those that enable the realisation of children's right to be heard within a school setting.

\section{A Participatory Rights Based Approach}

One of the exciting aspects to this research is that I will not be doing it alone, I will be advised throughout the process by a group of experts - ten children aged between five and eleven. Given that a fundamental premise of this research is that children have the right to voice their opinion in any matter that concerns them, as this research concerns children it is imperative that I 'walk the walk' and not just 'talk the talk' by honouring and facilitating this right within the research. While children's ability to participate in research has gained widespread recognition, children's rights discourse moves beyond the recognition of children's ability to participate in research by actively promoting their right to participate. My advisory group is contributing to how I conduct the research, the analysis of the data gathered and the dissemination of the research findings. There are many challenges to conducting participatory research with children, not least of which, is 
the need to use methods that are child centred and also navigating the level of decisionmaking power children possess as research participants. Another issue is the need to develop children's knowledge and understanding of the issue being researched in order for them to have the capacity to engage with the relevant research issues. There is a scarcity of research conducted with children in this manner, perhaps on account of limitations in the extent to which young children can contribute to adult-led research. Within a rights based approach however, the onus is on researchers to do so nonetheless. This research will, therefore, not only contribute to our knowledge regarding the barriers and enablers of children's right to be heard in a school context, but will also conritbute to filling the gap in to our knowledge regarding best practice in conducting adult-led participatory research with younger children.

\section{Conclusion}

Promoting children's voices within the classroom has been found to benefit both teaching and learning so it's a "win win" for pupils and teachers. Doing so, however, is not just good practice, it's an obligation. Both the United Nations Convention on the Rights of the Child as well as the Government of Ireland's National Policy Framework for Children and Young People 2014-2020 require that any adults who work with children do so in a manner that facilitates children's right to be heard. The difficulty is, knowing how to do this in a classroom of up to thirty children while at the same time ensuring that each child is provided with an education that meets strict predetermined learning outcomes. As a former preschool teacher, I am fully aware of how tremendous a challenge this actually is. This research will provide valuable guidance that will support teachers and educators in knowing how to develop a culture within their schools and a classroom that respects and facilitates children's voices. By providing evidence based recommendations and suggestions for teachers to draw on, this study will help to bridge the existing gap between policy and practice.

The author would like to thank her supervisors Dr. Deirdre Horgan and Dr. Jacqui O' Riordan for their on-going support and encouragement. This research is funded by the Irish Research Council. 